\title{
Hantavirus pulmonary syndrome in Canada: An overview of clinical features, diagnostics, epidemiology and prevention
}

\author{
Drebot $M A^{1 *}$, Jones $S^{1}$, Grolla $A^{1}$, Safronetz $D^{1}$, Strong JE${ }^{1}$, Kobinger $\mathbf{G}^{1}$, Lindsay $\mathrm{RL}^{1}$ \\ ${ }^{1}$ National Microbiology Laboratory, Public Health Agency of Canada, Winnipeg, MB \\ *Correspondence: mike.drebot@phac-aspc.gc.ca
}

\begin{abstract}
Hantavirus pulmonary syndrome is a disease caused by the inhalation of excreta from infected deer mice. In Canada, the majority of hantavirus pulmonary syndrome cases occur in the western provinces of British Columbia, Alberta, Saskatchewan and Manitoba and the primary cause of the illness is the Sin Nombre virus. Only one case of hantavirus pulmonary syndrome has been documented in eastern Canada (Québec); however, Sin Nombre virus-infected deer mice have been identified across the country. Although cases are rare (yearly case numbers range from zero to 13 and the total number of confirmed cases in Canada now total 109), the mortality rate among infected individuals is approximately $30 \%$. The majority of cases occur in the spring and early summer indicating seasonally-associated risk factors for viral exposure. In 2013 and 2014, a substantial increase in the number of hantavirus pulmonary syndrome cases was identified; however the cause remains unclear. No antivirals or vaccines are currently available and treatment is supportive. Public education, rodent control and the use of personal protective measures are key to avoid infections in at-risk populations.
\end{abstract}

\section{Introduction}

A 26 year old Canadian woman from the prairies was admitted to the intensive care unit in acute respiratory distress. She was previously healthy with no significant past medical history other than two normal pregnancies and deliveries; she had no allergies, no family history of asthma and no history of trauma. Approximately a week prior to admission she had started to feel unwell with a headache and low grade fever. One day prior to admission she began to have a dry cough and then increasing shortness of breath. On careful questioning, the husband had noted the only unusual event that occurred approximately two weeks before the onset of symptoms was that she had cleaned out their old garage, removing everything and then vacuuming it. At this time she had commented on the abundance of mouse droppings in the garage. An astute clinician sent blood samples to the National Microbiology Laboratory for diagnostic testing for hantavirus. Despite aggressive ventilator support and careful fluid administration, she developed overwhelming pulmonary edema, went into shock and died 24 hours after admission. Her infection with Sin Nombre virus was established by molecular and serological testing thus confirming that she had contracted hantavirus pulmonary syndrome.

Hantavirus pulmonary syndrome also known as hantavirus cardiopulmonary syndrome (HCPS) is a rare respiratory illness associated with the inhalation of aerosolized rodent excreta (urine and feces) contaminated by hantavirus particles $(1,2)$. Until recently, only four to six cases of hantavirus pulmonary syndrome were diagnosed per year in Canada. Most cases have occurred in Alberta but cases have also been reported in British Columbia, Saskatchewan, Manitoba and Québec $(3,4)$. In the past two years there has been a substantial increase in the yearly total of hantavirus pulmonary syndrome cases diagnosed in Canada. All cases occurred in rural settings and approximately $70 \%$ of the cases have been associated with domestic and farming activities.

The objective of this paper is to review the clinical features and laboratory diagnosis of this disease hantavirus pulmonary syndrome and describe the epidemiologic trends that have been observed in Canada between 1994 and 2014. 
Although four hantavirus species have been implicated as etiological agents of hantavirus pulmonary syndrome in North America (5), the Sin Nombre virus is most commonly associated with hantavirus pulmonary syndrome in Canada and the United States and its primary reservoir is the deer mouse, Peromyscus maniculatus $(3,6)$.

\section{Sin Nombre virus}

The Sin Nombre virus is a member of the Hantavirus genus (Family Bunyaviridae) $(7,8)$. The Bunyaviridae family is comprised of a large and diverse group of RNA viruses with a tripartite genome composed of $\mathrm{S}, \mathrm{M}$ and $\mathrm{L}$ segments. The family is currently composed of five genera, Orthobunyavirus, Nairovirus, Phlebovirus, Tospovirus and Hantavirus, all of which contain viruses of agricultural or medical importance. The hantavirus genus was conceived in 1983 and currently, the International Committee on the Taxonomy of Viruses recognizes more than 20 unique species within the hantavirus genus $(7,8)$. Approximately half of these species are associated with human diseases such as hemorrhagic fever with renal syndrome and hantavirus pulmonary syndrome. Spill-over is very rare and each hantavirus species is typically associated with a single rodent reservoir; co-evolution with rodent hosts has probably occurred for thousands and perhaps millions of years $(8,9)$.

\section{Transmission and incubation}

Sin Nombre virus is most frequently associated with inhalation of contaminated excreta. This is primarily from deer mice urine and less often with feces $(4,10,11,12)$ (Figure 1). The virus is also found in saliva and therefore bites are a potential route of transmission; however, few cases directly associated with mouse bites have been documented. Person-to-person transmission of hantavirus pulmonary syndrome has not been documented in North America but has been associated with Andes hantavirus infections in Chile and Argentina (9). Interestingly, person-to-person transmission of Andes hantavirus occurs mainly in family clusters and transmission risk is associated with close contact activities including sexual contact during the disease prodrome; nosocomial infections are rare but have been reported (13). The incubation period of hantavirus pulmonary syndrome has been determined to be between 9 and 33 days with a median time of symptom onset of 14 to 17 days postexposure, although incubation periods between 46 to 51 days have been reported (14, Drebot, unpublished observation).

Figure 1: Illustration of the typical cycle of transmission of hantaviruses

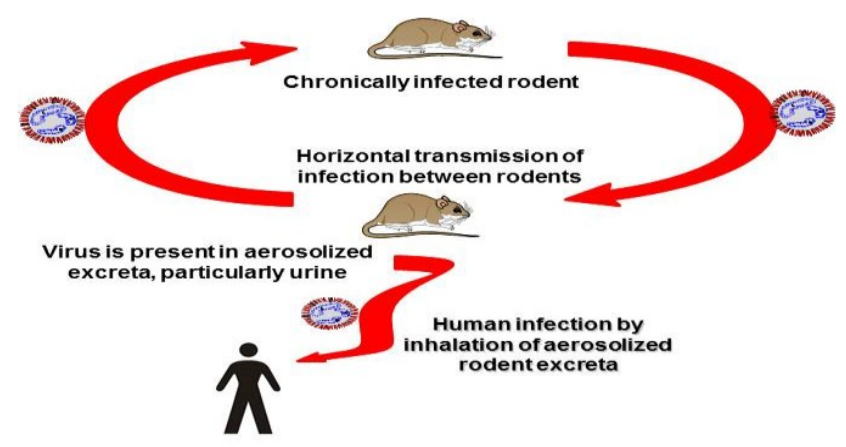

\section{Clinical features}

Hantavirus pulmonary syndrome is characterized by four phases of disease: febrile prodrome, cardiopulmonary, diuretic and convalescent $(1,14,15)$. Upon inhalation of Sin Nombre virus contaminated excreta, an extensive infection of pulmonary endothelial cells occurs and viremia is initiated (14). Following the incubation period, individuals usually experience the febrile prodrome characterized by fever, chills, occasional headaches and sometimes gastrointestinal symptoms. 
Clinical illness is characterized by a febrile illness $\left(>38.3^{\circ} \mathrm{C}\right)$ with bilateral diffuse interstitial edema that radiographically resemble acute respiratory distress syndrome. Respiratory compromise requiring supplemental oxygen often develops within 72 hours of hospitalization (1). Thrombocytopenia and elevated hematocrit levels are highly sensitive and specific features in detecting hantavirus pulmonary syndrome in suspect patients (16). Three to six days after the onset of initial symptoms the patient will enter the cardiopulmonary phase, typically manifesting with cough and shortness of breath; pulmonary edema and deterioration of cardiopulmonary function may then rapidly occur over the ensuing 24 hours. Death can occur within 48 hours due to respiratory failure, myocardial dysfunction and shock. Those who get through the cardiopulmonary phase proceed to the third (diuretic) phase and their prognosis is much better. Over two to four days, these patients rapidly improve, their symptoms resolve and so does their pulmonary edema. The final convalescent phase can last for months with persistent weakness, fatigue and abnormal pulmonary function $(1,4)$.

\section{Treatments and vaccines}

There are no proven antiviral therapies for hantavirus pulmonary syndrome and vaccines are currently not available (17). Clinical management depends on careful fluid administration and ventilatory support. If available, the use of extracorporeal membrane oxygenation for advanced hantavirus pulmonary syndrome is a consideration. Generally extracorporeal membrane oxygenation is reserved for advanced hantavirus pulmonary syndrome and has historically been associated with poor survival rates. The procedure has been used with a significant degree of success at the University of New Mexico with almost $70 \%$ of severe cases recovering after treatment but must be initiated quickly once advanced shock or respiratory failure develops $(14,17)$.

\section{Risk factors and prevention}

Risk factors for infection with hantaviruses usually include involvement in outdoor activities such as rural- and forest-related activities, peridomestic infestation of premises by rodents, exposure to potentially infected dust and outdoor military training (18). Case-control studies in the US, have identified peridomestic cleaning, agricultural activities and increased numbers of small mammals within households as risk factors for hantavirus pulmonary syndrome $(19,20)$ as well as entering or cleaning rarely used, rodent-infested structures $(21)$. Key components of prevention are focused on safe rodent handling, disinfection and rodent exclusion methods (22) and disease prevention is primarily delivered through public education. Personal risk reduction measures include recognizing rodents / evidence of rodent infestation, preventing rodents from entering the home, use of appropriate procedures (e.g., ventilation) and the use of personal protective equipment and disinfectants when cleaning or entering areas contaminated with mouse droppings $(3,22)$.

\section{Laboratory diagnosis}

Laboratory criteria for diagnosis includes any of the following: presence of hantavirus-specific lgM or a fourfold or greater increase in IgG antibody titres, a positive reverse transcriptase-polymerase chain reaction (RT-PCR) amplification of viral RNA, or a positive immunohistochemical result for hantavirus antigen in a patient's tissue. Isolation of the virus from clinical samples is difficult and is not usually carried out during investigations of suspect cases $(1,4,14)$.

The gold-standard diagnosis of hantavirus pulmonary syndrome is based upon the detection of hantavirus-specific antibodies (4). Antibodies of the immunoglobulin (lg) M class are present during the earliest clinical stages of hantavirus pulmonary syndrome. IgG antibodies against structural Sin Nombre virus proteins such as the nucleocapsid (N) or G1 / Gn glycoprotein can quite often be detected even in the prodrome phase $(1,4)$.

\section{Epidemiology in Canada}

Canada has adopted the hantavirus pulmonary syndrome case definition recommended by the Pan American Health Organization (1). A confirmed case is a person with clinical illness and laboratory confirmation of infection. Active surveillance for hantavirus pulmonary syndrome began in 1994 and it was made a nationally notifiable disease in January 2000 (3). As of December 31, 2014 a total of 109 laboratory-confirmed cases of hantavirus pulmonary syndrome have been documented in Canada (Kobinger, Grolla, Jones, Lindsay, Drebot and Strong, unpublished observation) and over 600 cases have been identified in the US $(6,23)$. An average of four to five hantavirus pulmonary syndrome cases have been diagnosed annually with yearly numbers fluctuating between 0 
and 13 cases (Figure 2). Three retrospective cases were identified in 1989, 1990 and 1992 after active surveillance was initiated in 1994.

Figure 2: Distribution and total number of hantavirus pulmonary syndrome cases $(n=109)$ reported in Canada, 1989 to 2014

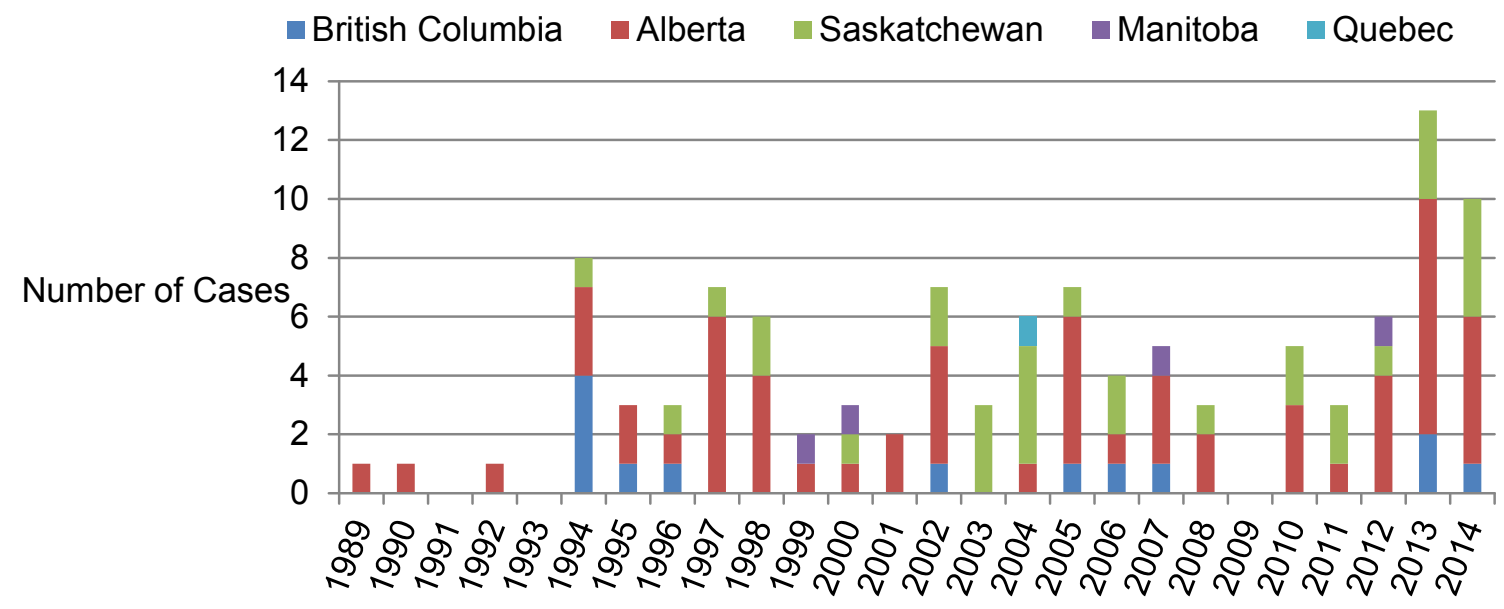

Years

In 2013 and 2014, there were 13 and 10 cases identified respectively; a marked increase in hantavirus pulmonary syndrome cases compared to previous years (Figure 2). Cases of hantavirus pulmonary syndrome have been diagnosed in every month, although there is an obvious spring and early summer peak of infections, with over $60 \%$ of the cases occurring between April and July (Figure 3). The average age of cases has been 40 years old (range seven to 76 ) and the majority of cases have been male $(67 \%, 74 / 109)$. The current documented case fatality rate in Canada is $29 \%$ (30/105) (the outcome of four patients is unknown), with higher mortality rates observed in females (39\%) compared with males (24\%). Case numbers and mortality rates are typically lower for children (zero to 10 years of age) and elderly individuals (60+ years), with the majority of infections occurring in teenagers (13 to 19 years old; $9.1 \%$ of all hantavirus pulmonary syndrome cases), young adults (20 to 40 years old; $33.6 \%$ ) and middle-aged (41 to 60 years old; $50 \%$ ) individuals. A similar age-specific pattern of hantavirus pulmonary syndrome cases has been reported in the United States (6) and it is unclear why children appear to be at lower risk for hantavirus pulmonary syndrome. It should be noted that mild and subclinical cases of hantavirus pulmonary syndrome can occur for a minority of infections, so physicians should be aware of a wider spectrum of disease severity $(24,25)$. 
Figure 3: Seasonal distribution of hantavirus pulmonary syndrome cases (HPS) in Canada ( $n=109$ )

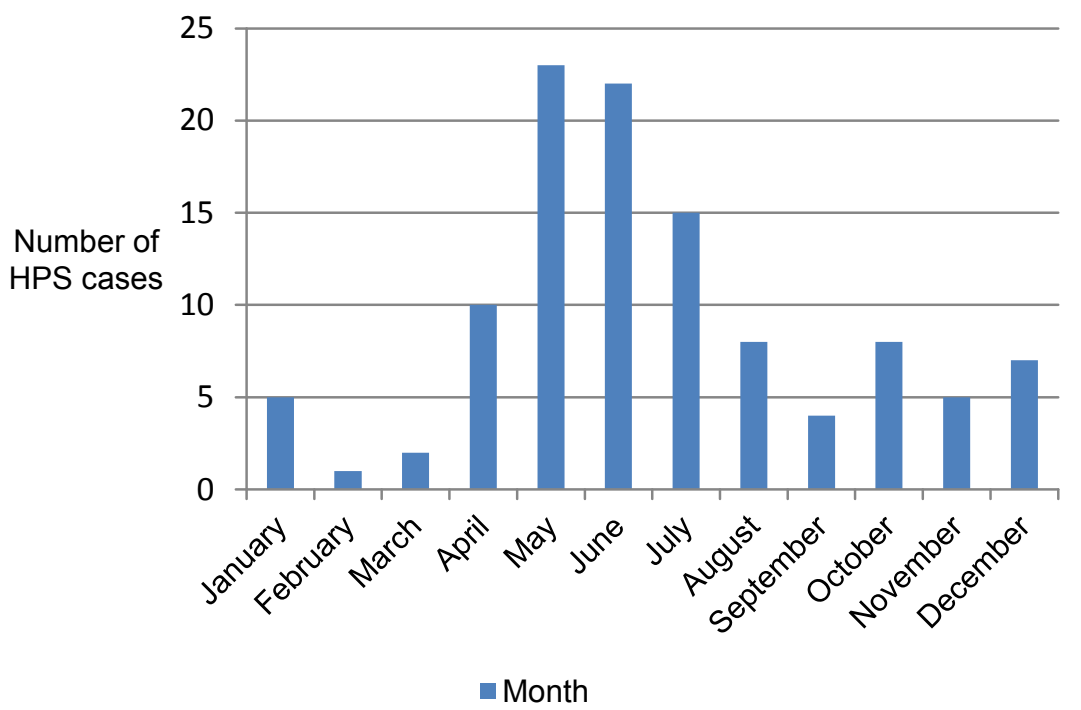

Despite the detection of Sin Nombre virus-infected mice from across Canada, $99 \%$ of the cases of hantavirus pulmonary syndrome have occurred in the four western provinces either within or on the edge of the Western Plains geographic area. Only a single case has been reported in eastern Canada (Québec) (Figure 2). Alberta accounts for over half the hantavirus pulmonary syndrome cases diagnosed with 60 of the 109 cases reported $(55 \%)$. A similar western-biased spatial pattern of hantavirus pulmonary syndrome cases is observed in the US (6, 23, 26). Spatial clustering of hantavirus pulmonary syndrome cases does occur and multiple human infections associated with a common exposure to rodent droppings (e.g., a cleaning event) have been observed on two occasions (27). Nucleotide sequence analysis of Sin Nombre virus M and S genomic segments from infected deer mice collected in Canada has demonstrated genetic polymorphisms / fingerprints which correlate with the geographic location of collection (28). However, it is uncertain if western strains of the Sin Nombre virus are more virulent than eastern strains, or if other, as yet undetermined factors, are responsible for the disproportionate number of cases of hantavirus pulmonary syndrome occurring in western Canada. The genetics of deer mouse populations and inherent differences in viral prevalence of Sin Nombre virus are other factors that may play a role in the disjunctive distribution of hantavirus pulmonary syndrome cases in Canada and warrant further investigation (28).

Two imported cases of hantavirus pulmonary syndrome (one each from Bolivia and Argentina) have also been reported in Canada $(4,29)$. One of the imported cases involved a Canadian who had travelled to Argentina and became ill a week after arriving back at his residence in Saskatchewan. The individual was diagnosed by serological testing as having been exposed to a hantavirus and died shortly after being identified as an hantavirus pulmonary syndrome case. The patient had spent several weeks in Argentina, however it was possible that the individual had been infected upon his return to Canada. Determining the country where he was actually exposed could not be initially verified due to the possible serological cross reactivity of Canadian and South American hantaviruses. The identification and phylogenetic characterization of hantavirus RNA in the patient's blood clots verified that the infection was associated with an Argentinean hantavirus related to the Andes virus lineage. The use of PCR and amplicon sequencing not only verified the country in which the patient was exposed to the virus but also provided a timeline that indicated an incubation period of over a month between exposure and symptom onset. Similar molecular epidemiology procedures were used to identify the imported case from Bolivia (29).

\section{Molecular epidemiology}

Although genetic identification and characterization of the infecting virus is not always possible, when appropriate samples (e.g., acute whole blood) are available and polymerase chain reaction amplicon sequencing is performed, Sin Nombre virus has always been identified as the etiological agent of hantavirus pulmonary syndrome in Canada. Consistent with previous phylogenetic characterization of Sin Nombre virus from infected 
deer mice in Canada, the genotype of the virus associated with hantavirus pulmonary syndrome cases corresponds with a western Canadian genogroup / clade ((28), Grolla et al, unpublished observation). Field investigations involving the comparisons of virus sequences from mice collected near where patients have resided / worked have demonstrated a high degree of genetic relatedness and in certain instances exact matches (Drebot and Lindsay, unpublished observation). The ability to identify mice carrying the strain of virus associated with a hantavirus pulmonary syndrome case may assist in distinguishing among multiple sites of possible exposures (including verification of imported cases). The elegant epidemiological investigation conducted by Jay et al. 1995 (30) demonstrates the utility that molecular epidemiology has to improve our understanding of the risk factors (and point sources for infection) associated with hantavirus infection (31).

\section{Rodent surveillance}

In Canada, the ubiquitous deer mouse is the primary reservoir for Sin Nombre virus while other species of hantaviruses have been detected (e.g., Prospect Hill virus) in red-backed voles (3). To date, disease has not been associated with non-Sin Nombre virus species in Canada (Strong, Golla, Kobinger and Drebot, unpublished observation). Based on passive surveillance for hantaviruses in rodents, Sin Nombre virus-infected mice have been detected in every province except Prince Edward Island and Nova Scotia $(3,28)$. To-date, there is evidence of Sin Nombre virus-infected mice in Yukon but not in the Northwest Territories or Nunavut. However, only limited numbers of deer mice have been tested from the Northwest Territories, therefore Sin Nombre virus may be circulating in this and other regions of Canada. The distribution of Sin Nombre virus-infected mice is discontinuous and focal with some deer mouse populations uninfected while others, in relatively close proximity, displaying high rates of seroprevalence (>30\% [3]).

\section{Discussion}

Hantavirus pulmonary syndrome is a rare disease; however, there has been a surge in cases noted in the last two years indicating that there continues to be a risk for infection in Canadian localities where the virus circulates. The majority of exposures to Sin Nombre virus result in severe disease, but hantavirus infections should also be considered in the differential diagnosis for nonspecific febrile illness. This is especially relevant for persons with known exposure to rodents or their excreta, usually as a result of cleaning, rodent-infested structures in western Canada (3). In addition, it is possible that cases without severe pulmonary involvement may have gone undiagnosed for a minority of patients $(24,25,27)$.

Sin Nombre virus infects deer mice across Canada; however, almost all human cases of hantavirus pulmonary syndrome occur in the western provinces of British Columbia, Alberta, Saskatchewan and Manitoba. Although case numbers are low relative to other infectious diseases, the fatality rate remains at approximately $30 \%$ despite increased awareness of hantavirus pulmonary syndrome. Cases of hantavirus pulmonary syndrome have been reported in every month of the year but most occur in the spring and early summer. Seasonal specific-risk factors related to cleaning of structures (e.g., cottage- or farm-associated machinery or buildings) and the increased potential contact with deer mouse excreta at this time of year likely contributes to the seasonality of hantavirus pulmonary syndrome cases $(3,6,32)$.

The number of hantavirus pulmonary syndrome cases in Canada has noticeably increased over the last two years and this trend should be closely monitored. The reason for the higher numbers of hantavirus pulmonary syndrome cases remains unclear; however, it is speculated that the recent upswing in hantavirus pulmonary syndrome cases could be driven by atypically large deer mouse populations that may have resulted from milder winters and an associated increase in reproductive output of local deer mouse populations. Larger infected mouse populations may have led to increased opportunities for human exposure to infected excreta and hence a higher risk of transmission of hantavirus infection to humans (12).

\section{Conclusion}

Hantavirus pulmonary syndrome is a rare rodent-borne disease that occurs primarily in western North America, Central America and South America. Prevention of this disease can be achieved through public education about the risks associated with exposure to rodents and their excreta and the use of appropriate preventive practices. Public health authorities should continue to update and modify existing messaging in order to enhance the uptake 
of key protective behaviours by at-risk populations in Canada. Travellers should also be reminded of the risk of hantaviruses and actions to prevent infection while abroad as imported cases of hantavirus pulmonary syndrome have been reported $(4,29)$. Several key research questions remain unanswered including why the number of HPS cases have increased in recent years as well as why the majority of cases occur in the western provinces (and states) despite the fact that Sin Nombre virus-infected deer mice have been identified across Canada.

\section{Acknowledgements}

The authors wish to acknowledge the Canadian provincial public health laboratories for their assistance in the investigation and documentation of hantavirus pulmonary syndrome cases and the technical assistance of Melissa David in helping generate the figures in this article.

\section{Conflict of interest}

None.

\section{References}

(1) Pan-American Health Organization. Hantaviruses in the Americas: Guidelines for prevention, diagnosis, treatment, prevention and control. Washington, US: PAHO, Technical Paper 47;1999.

(2) Klein SL, Calisher CH. Emergence and persistence of hantaviruses. Curr Top Microbiol Immunol. 2007;315:217-52.

(3) Drebot MA, Artsob H, Werker D. Hantavirus pulmonary syndrome in Canada, 1989-1999. Can Commun Dis Rep. 2000;26:65.

(4) Drebot MA, Safronetz D. Sin Nombre Virus. In: Dongyou Liu, editor. Molecular detection of human viral pathogens. Boca Raton, FL: CRC Press, Taylor and Francis Group; 2011. p. 691-701.

(5) Graziano KL, Tempest B. Hantavirus pulmonary syndrome: A zebra worth knowing. Am Fam Physician. 2002 Sep 15;66(6):1015-20.

(6) Reported cases of HPS [Internet]. [updated April 14, 2014]. http://www.cdc.gov/hantavirus/surveillance/index.html.

(7) Bunyaviruses [Internet]. [updated 29 August 2010]. http://ictvdb.bio-mirror.cn/lctv/fs_bunya.htm.

(8) Kruger DH, Figueiredo LT, Song JW, Klempa B. Hantaviruses--globally emerging pathogens. J Clin Virol. 2015 Mar;64:128-36.

(9) Figueiredo LT, Souza WM, Ferres M, Enria DA. Hantaviruses and cardiopulmonary syndrome in South America. Virus Res. 2014 Jul 17;187:43-54.

(10) Safronetz D, Lindsay R, Dibernardo A, Hjelle B, Xiao R, Artsob H, et al. A preliminary study of the patterns of Sin Nombre viral infection and shedding in naturally infected deer mice (Peromyscus maniculatus). Vector Borne Zoonotic Dis. 2005;5(2):127-32.

(11) Safronetz D, Drebot MA, Artsob H, Cote T, Makowski K, Lindsay LR. Sin Nombre virus shedding patterns in naturally infected deer mice (Peromyscus maniculatus) in relation to duration of infection. Vector Borne Zoonotic Dis. 2008;8(1):97-100.

(12) Mills JN, Amman BR, Glass GE. Ecology of hantaviruses and their hosts in North America. Vector Borne Zoonotic Dis. 2010 Aug;10(6):563-74.

(13) Martinez-Valdebenito C, Calvo M, Vial C, Mansilla R, Marco C, Palma RE, et al. Person-to-person household and nosocomial transmission of andes hantavirus, Southern Chile, 2011. Emerg Infect Dis. 2014 Oct;20(10):1629-36.

(14) Mertz GJ, Hjelle B, Crowley M, Iwamoto G, Tomicic V, Vial PA. Diagnosis and treatment of new world hantavirus infections. Curr Opin Infect Dis. 2006 Oct;19(5):437-42.

(15) Enria DA, Briggiler AM, Pini N, Levis S. Clinical manifestations of New World hantaviruses. Curr Top Microbiol Immunol. 2001;256:117-34.

(16) Knust B, Macneil A, Rollin PE. Hantavirus pulmonary syndrome clinical findings: Evaluating a surveillance case definition. Vector Borne Zoonotic Dis. 2012 May;12(5):393-9.

(17) Jonsson CB, Hooper J, Mertz G. Treatment of hantavirus pulmonary syndrome. Antiviral Res. 2008 Apr;78(1):162-9.

(18) Watson DC, Sargianou M, Papa A, Chra P, Starakis I, Panos G. Epidemiology of Hantavirus infections in humans: A comprehensive, global overview. Crit Rev Microbiol. 2014 Aug;40(3):261-72.

(19) Childs JE, Krebs JW, Ksiazek TG, Maupin GO, Gage KL, Rollin PE, et al. A household-based, case-control study of environmental factors associated with hantavirus pulmonary syndrome in the southwestern United States. Am J Trop Med Hyg. 1995 May;52(5):393-7.

(20) Zeitz PS, Butler JC, Cheek JE, Samuel MC, Childs JE, Shands LA, et al. A case-control study of hantavirus pulmonary syndrome during an outbreak in the southwestern United States. J Infect Dis. 1995 Apr;171(4):864-70.

(21) Armstrong LR, Zaki SR, Goldoft MJ, Todd RL, Khan AS, Khabbaz RF, et al. Hantavirus pulmonary syndrome associated with entering or cleaning rarely used, rodent-infested structures. J Infect Dis. 1995 Oct;172(4):1166. 
(22) Mills JN, Corneli A, Young JC, Garrison LE, Khan AS, Ksiazek TG. Hantavirus pulmonary syndrome--United States: Updated recommendations for risk reduction. Centers for Disease Control and Prevention. MMWR Recomm Rep. 2002 Jul 26;51(RR-9):1-12.

(23) Knust B, Rollin PE. Twenty-year summary of surveillance for human hantavirus infections, United States. Emerg Infect Dis. 2013 Dec;19(12):1934-7.

(24) MacDougal L, Fyfe M, Bowie WR, Cooper K, McCauley GD, Morshed M. Hantavirus infection in British Columbia: An atypical case history and epidemiological review. BCMJ. 2005;47:234.

(25) Nunez JJ, Fritz CL, Knust B, Buttke D, Enge B, Novak MG, et al. Hantavirus infections among overnight visitors to Yosemite National Park, California, USA, 2012. Emerg Infect Dis. 2014 Mar;20(3):386-93.

(26) Douglass RJ, Calisher $\mathrm{CH}$, Bradley KC. State-by-state incidences of hantavirus pulmonary syndrome in the United States, 1993-2004. Vector Borne Zoonotic Dis. 2005 Summer;5(2):189-92.

(27) Webster D, Lee B, Joffe A, Sligl W, Dick D, Grolla A, et al. Cluster of cases of hantavirus pulmonary syndrome in Alberta, Canada. Am J Trop Med Hyg. 2007;77(5):914-8.

(28) Drebot MA, Gavrilovskaya I, Mackow ER, Chen Z, Lindsay R, Sanchez AJ, et al. Genetic and serotypic characterization of Sin Nombre-like viruses in Canadian Peromyscus maniculatus mice. Virus Res. 2001;75(1):75-86.

(29) Reynolds S, Galanis E, Krajden M, Morshed M, Bowering D, Abelson W, et al. Imported fatal hantavirus pulmonary syndrome. Emerg Infect Dis. 2007 Sep;13(9):1424-5.

(30) Jay M, Hjelle B, Davis R, Ascher M, Baylies HN, Reilly K, et al. Occupational exposure leading to hantavirus pulmonary syndrome in a utility company employee. Clin Infect Dis. 1996 May;22(5):841-4.

(31) Hjelle B, Torrez-Martinez N, Koster FT, Jay M, Ascher MS, Brown T, et al. Epidemiologic linkage of rodent and human hantavirus genomic sequences in case investigations of hantavirus pulmonary syndrome. J Infect Dis. 1996 Apr;173(4):781-6.

(32) Richardson KS, Kuenzi A, Douglass RJ, Hart J, Carver S. Human exposure to particulate matter potentially contaminated with Sin Nombre virus. Ecohealth. 2013 Jun;10(2):159-65. 